\title{
Ellagitannins of the fruit rind of pomegranate (Punica granatum) antagonize in vitro the host inflammatory response mechanisms involved in the onset of malaria
}

\author{
Mario Dell'Agli*1, Germana V Galli', Michela Bulgari' ${ }^{1}$ Nicoletta Basilico², Sergio Romeo³, Deepak Bhattacharya4
} Donatella Taramelli² and Enrica Bosisio ${ }^{1}$

\begin{abstract}
Background: The sun-dried rind of the immature fruit of pomegranate (Punica granatum) is presently used as a herbal formulation (OMARIA, Orissa Malaria Research Indigenous Attempt) in Orissa, India, for the therapy and prophylaxis of malaria. The pathogenesis of cerebral malaria, a complication of the infection by Plasmodium falciparum, is an inflammatory cytokine-driven disease associated to an up-regulation and activity of metalloproteinase- 9 and to the increase of TNF production. The in vitro anti-plasmodial activity of Punica granatum (Pg) was recently described. The aim of the present study was to explore whether the anti-malarial effect of OMARIA could also be sustained via other mechanisms among those associated to the host immune response.
\end{abstract}

Methods: From the methanolic extract of the fruit rind, a fraction enriched in tannins (Pg-FET) was prepared. MMP-9 secretion and expression were evaluated in THP-1 cells stimulated with haemozoin or TNF. The assays were conducted in the presence of the Pg-FET and its chemical constituents ellagic acid and punicalagin. The effect of urolithins, the ellagitannin metabolites formed by human intestinal microflora, was also investigated.

Results: Pg-FET and its constituents inhibited the secretion of MMP-9 induced by haemozoin or TNF. The effect occurred at transcriptional level since MMP-9 mRNA levels were lower in the presence of the tested compounds. Urolithins as well inhibited MMP-9 secretion and expression. Pg-FET and pure compounds also inhibited MMP-9 promoter activity and NF-kB-driven transcription.

Conclusions: The beneficial effect of the fruit rind of Punica granatum for the treatment of malarial disease may be attributed to the anti-parasitic activity and the inhibition of the pro-inflammatory mechanisms involved in the onset of cerebral malaria.

\section{Background}

Pomegranate (Punica granatum L., Punicaceae) is used in the traditional medicine of different Asian cultures for the treatment of a variety of ailments. In Ayurvedic medicine, the plant, described under its Sanskrit name "dalima" (fruit), is considered as a "blood tonic" and used to cure parasitic infections [1]. The decoction of the root was found beneficial in fevers and chronic debility due to

* Correspondence: mario.dellagli@unimi.it

1 Dipartimento di Scienze Farmacologiche, Università degli Studi di Milano, Via Balzaretti, 9 - 20133 Milano, Italy

Full list of author information is available at the end of the article malaria. Moreover, the fruit rind powder was found to possess immunomodulatory properties [2].

The eastern province of Orissa (India) is an area endemic for both Plasmodium falciparum and Plasmodium vivax; malaria constitutes a major health problem for the population, in particular for those living in rural areas. Since 1998, malaria patients referring to the Ayurveda dispensary receive a herbal preparation named OMARIA, made of sun-dried rind of the immature P. granatum fruits $(P g)$. OMARIA (the acronym for Orissa Malaria Research Indigenous Attempt) is distributed as a home based economic remedy for prophylaxis under the 
banner "Fight Malaria At Home/Ghare Maro Malaria. Clinical application started in 1998 by the Indian Red Cross Society Charitable Ayurveda dispensary (c/o District Magistrate Koraput) on behalf of D. Bhattacharya. Dispensary records indicate that OMARIA can successfully control $P$. falciparum and $P$. vivax infections in all patients including infants and pregnant women $[3,4]$. OMARIA is administered as gelatine capsules (courtesy of $\mathrm{m} / \mathrm{s}$ Sunil Health Care Ltd. New Delhi, India), containing each 825-850 $\mathrm{mg}$ of $\mathrm{Pg}$. The therapeutic dose is one capsule every eight hours for three consecutive days. For prophylaxis, one capsule has to be taken in every day (children receive half the dosages) for a period ranging between two or four weeks/six months. Records from the Ayurveda-Indian Red Cross Society indicate a positive impact on the health status of the population under OMARIA coverage: the prophylactic intervention appears not only to reduce malaria episodes, but also the incidence of other infectious diseases, such as measles, chicken pox and conjunctivitis [4].

The reported anti-malarial effectiveness of the OMARIA was attributed to the anti-parasitic activity of a fraction enriched in tannins $(P g$-FET) obtained from the $P g$ methanolic extract [5]. The effect could be attributed to different constituents of $P g$-FET, namely ellagic acid (EA), and punicalagin, which inhibited in vitro the growth of $P f$ asexual blood stages [5,6]. Whether $P g$ preparations could help to control the malarial disease by adjuvant mechanisms, as well, remains unexplored. The present research was undertaken with the aim of testing the effects of Pg preparations on the pathways involved in the onset severe malaria, which may develops during $P f$ infection.

It is largely accepted that severe malaria is an inflammatory cytokine-driven disease. There is remarkable evidence that tumour necrosis factor (TNF) and interleukin1 are important contributors to the systemic disease caused by the infectious agent $P f[7,8]$.

The innate immune system seeks to destroy the protozoa and remove the remnants via phagocytosis by monocytes and neutrophils. Circulating levels of TNF, a mediator of the innate immune system, are increased after infection, as a consequence of stimulation of monocyte-macrophages by infected red blood cells (IRBC) or phagocytosis of haemozoin $(\mathrm{Hz}$, the malarial pigment) phagocytosis by human monocytes [9-12]. TNF in turn enhances the synthesis of metalloproteinase-9 (MMP-9) in monocytes and macrophages $[9,10]$. More recently, it has been shown that human monocytes fed with $\mathrm{Hz}$ or IRBC display increased MMP-9 activity and protein/ mRNA expression and increased production of TNF and a role of MMP-9 and TNF in the onset of cerebral malaria has been postulated $[11,12]$.

The wide-range of therapeutic benefits of pomegranate have been attributed to its anti-oxidant and anti-inflam- matory properties. It was shown that $P g$ fruit juice and its constituents ellagitannins, have a significant and broad inhibitory effect on MMPs, including MMP-9 [13,14,1]. In addition, $P g$ fruit juice and ellagitannins suppress inflammatory cell signalling induced by TNF in colon cancer cells [15].

However, it was not clear which of the compounds present in $P g$-FET or ellagitannins could antagonize the host inflammatory response. In the present study, it has been investigated whether $P g$-FET, EA, and punicalagin, the compounds previously identified in $P g$-FET, inhibited MMP-9 upregulation and secretion in THP-1 cells induced by native haemozoin $(\mathrm{Hz})$ and TNF. Since ellagitannins were shown to be converted by the human gut microflora into urolithin A, B and urolithin-8-methylether [16-20] these metabolites were also evaluated for their inhibitory effect.

Here, it is shown that $P g$-FET and its constituents EA and punicalagin, all inhibited the MMP-9 secretion and expression in THP-1 cells, fed with Hz or TNF. Pg-FET and individual compounds were also able to inhibit MMP-9 promoter activity after stimulation with $\mathrm{Hz}$. The inhibitory effect was partially due to the inhibition of NF$\kappa \mathrm{B}$ pathway. Urolithins were also active. It is then plausible that $P g$, in addition to the direct effect on the parasite, modulates the malarial disease via the inhibition of the inflammatory response induced by haemozoin.

\section{Methods \\ Chemicals}

Amberlite XAD16 resin was purchased from SigmaAldrich (Milan-Italy) and Kollidon from BASF Chemical Company (Germany). Ellagic acid (EA) was acquired from Fluka-Sigma-Aldrich (Milan, Italy), punicalagin was obtained from AvaChem Scientific LLC, San Antonio, Texas, USA. Urolithin A, B and urolithin A-8-methylether were synthesized as described [5]. All reagents were purchased from Fluka-Sigma-Aldrich (Milan, Italy).

\section{Plant material and extract fractionation}

The pomegranate immature fruit was manually plucked from plants growing in tropical forest area of India. The fruits were cut and the arils discarded. The rind was sundried, finely ground, delipidized by petroleum ether (40:60) and extracted twice with methanol $(\mathrm{MeOH}, 1 \mathrm{~g} /$ $10 \mathrm{ml})$. The $\mathrm{w} / \mathrm{w}$ yield of the $\mathrm{MeOH}$ extract was $38 \%$ with respect to the starting crude material. For the tannin removal, the extract was treated with Kollidon $(1: 25$, w/ w) thus obtaining $P g$-MeOH-DT.

For the preparation of a fraction enriched in tannins $(P g$-FET), $5 \mathrm{~g}$ of the $\mathrm{Pg}$ - $\mathrm{MeOH}$ extract were dissolved in $500 \mathrm{ml}$ of water and chromatographed on Amberlite XAD16 resin as described [5]. The w/w yield of $P g$-FET 
was $60 \%$ with respect to the $P g-\mathrm{MeOH}$ extract. $P g$-FET was analyzed by HPLC-MS as described [5].

\section{Purification of native haemozoin}

Plasmodium falciparum cultures were carried out according to the method of Trager and Jensen with slight modifications [21]. Briefly, a chloroquine (CQ)-sensitive P. falciparum strain (D10) was maintained at 5\% haematocrit at $37^{\circ} \mathrm{C}$ in complete culture medium (RPMI 1640 supplemented with $\mathrm{NaHCO}_{3} 24 \mathrm{mM}, 1 \%$ AlbuMax II, $0.01 \%$ hypoxanthine, $20 \mathrm{mM}$ HEPES, and $2 \mathrm{mM}$ glutamine). All cultures were maintained in a standard gas mixture, consisting of $1 \% \mathrm{O}_{2}, 5 \% \mathrm{CO}_{2}, 94 \% \mathrm{~N}_{2}$.

To separate haemozoin, cells were washed twice with serum-free culture medium, resuspended to $25 \%$ haematocrit, and fractionated onto a discontinuous Percoll $/ 4 \%$ sorbitol (w/v) gradient $(0,40,80 \%)$. After centrifugation at $1075 \mathrm{~g}$, native haemozoin was collected from the top of the gradient, $0-40 \%$ interphase. Native haemozoin was washed three times with PBS and stored at $20 \%(\mathrm{v} / \mathrm{v})$ in PBS at $-20^{\circ} \mathrm{C}$. The haem content of $\mathrm{HZ}$ was determined by building a standard curve with increasing concentrations of haemin $(0-100 \mu \mathrm{M})$ and measuring absorbance at $405 \mathrm{~nm}$ of a weighed amount of the compound dissolved in $0.1 \mathrm{M} \mathrm{NaOH}$.

\section{Cell cultures}

Human THP-1 monocytic leukaemia cells (ATCC, Teddington, UK) were grown in RPMI 1640 (Invitrogen s.r.l., Milano, Italy) supplemented with 100 units penicillin $/ \mathrm{ml}$, $100 \mu \mathrm{g}$ streptomycin/ml, $10 \mathrm{mM}$ HEPES, $1 \mathrm{mM}$ Sodium Pyruvate, $0.05 \mathrm{mM}$ beta-mercaptoethanol, and 10\% heatinactivated foetal calf serum (FCS, Euroclone, Milano, Italy).

$P g$-FET was used at $50-100 \mu \mathrm{g} / \mathrm{ml}$. Concentrations were chosen by taking into consideration the daily dosage of P.g. $(2550 \mathrm{mg} /$ die), the recovery of the $\mathrm{MeOH}$ extract, the percentage of FET in the $\mathrm{MeOH}$ extract and assuming complete absorption.

$P g$-FET and pure compounds were used at no toxic concentrations. Cytotoxicity was evaluated by testing alterations of mitochondrial functionality as assessed by MTT test [22]. No sign of cytotoxicity was observed at concentrations ranging from 50 to $250 \mu \mathrm{g} / \mathrm{ml}$ for FET and $25 \mu \mathrm{M}$ for individual compounds.

To evaluate the effect of $P g-\mathrm{MeOH}$ extract on the MMP-9 secretion in PMA-treated THP-1, $1.2 \times 10^{6}$ cells/ $\mathrm{ml}$ were plated in 24-well plates in the presence of $10 \mathrm{nM}$ PMA to induce differentiation to macrophages. After 48 hours, cells were treated with the extract for 24 hours by using RPMI 1640 deprived of FCS, and the medium collected and subject to zymography.

To evaluate the effect of the fraction/compounds on TNF-induced MMP-9 secretion, THP-1 cells were plated in 96-well plated $\left(1 \times 10^{6} \mathrm{cells} / \mathrm{ml}\right)$ in the presence of 10 $\mathrm{ng} / \mathrm{ml} \mathrm{TNF}$, and treated with the compounds under study or the only vehicle (final concentration $0.1 \%$ ) by using medium deprived of FCS. 48 hours after, cells were centrifuged and the media collected for zymography.

To evaluate the effect on HZ-induced MMP-9 secretion, THP-1 cells were plated in 96-well plates $\left(1 \times 10^{6}\right.$ cells $/ \mathrm{ml}$ ) in the presence of $6 \mu \mathrm{g} / \mathrm{ml} \mathrm{HZ}$ and incubated at $37^{\circ} \mathrm{C}$ for four hours. Cells were centrifuged and resuspended in RPMI 1640 without FCS in the presence of the compounds under study or the vehicle. 48 hours after, cells were centrifuged and used for RNA extraction and protein measurement, whereas the media were subject to zymography.

\section{SDS-PAGE zymography}

The gelatinolytic activity of MMP-9 secreted by THP-1 cells was evaluated as previously described [23]. Briefly, cells were exposed to TNF or HZ in the presence of the tested compounds. Epigallocatechin-3-gallate (EGCg) 20 $\mu \mathrm{M}$ was used as reference inhibitor of MMP- 9 expression [23]. Control samples received the vehicle only. Aliquots of conditioned medium underwent electrophoresis on $7.5 \%$ polyacrylamide gels containing $10 \%$ SDS and gelatin $(1 \mathrm{mg} / \mathrm{ml})$. The gels were then washed in $2.5 \%$ Triton X100 (Sigma-Aldrich, Milan, Italy) at room temperature and then incubated overnight at $37^{\circ} \mathrm{C}(50 \mathrm{mM}$ Tris $\mathrm{pH} 7.5$ containing $150 \mathrm{mM} \mathrm{NaCl}, 10 \mathrm{mM} \mathrm{CaCl}, 1 \mu \mathrm{M} \mathrm{ZnCl}_{2}$; activation buffer). At the end of the incubation, the gels were stained with Coomassie brilliant blue R-250 (SigmaAldirch, Milan, Italy). For the quantification of zymograms, densitometric scanning was performed using QuantityOne software (Bio-Rad) and each lysis area was normalized against intracellular protein content determined by Bradford assay [24].

\section{Real time RT-PCR}

THP-1 cells were treated as described above. Total RNA was extracted with the RNeasy Mini Kit (Qiagen, S.p.A., Milan, Italy) according to the manufacturer's instructions. Total RNA was quantified using the Ribo Green RNA Quantitation Assay from Molecular Probes (Invitrogen, Milan, Italy). Aliquots corresponding to $1000 \mathrm{ng}$ of total RNA were reverse transcribed by using the iScript ${ }^{\mathrm{tm}} \mathrm{cDNA}$ synthesis kit (Bio-Rad Laboratories, Milan, Italy) following the manufacturer's protocol. Aliquots of the cDNA were subject to real-time PCR with a SYBR Green kit (Bio-Rad Laboratories, Milan, Italy) following the manufacturer's instructions. $18 \mathrm{~S}$ rRNA was used as the housekeeping gene for sample normalization and was amplified in separate wells within the same plate. Primers for real-time PCRs were designed with Primer Express software (Applied Biosystems, Monza, Italy) and optimized to work in a two-step protocol. The oligonucle- 
otides were synthetized by Primm (Milan, Italy) and the sequences are the following: MMP-9, forward primer 5'AAACCGAGTTGGAACCACGA3', reverse primer 5'T CAGGGAGACGCCCATTTC3'; 18 S rRNA forward primer 5'CGGCTACCACATCCAAGGAA3', reverse primer 5'AGGTAGTGACGAAAAATAACAATCACGG 3'. The specificity of the amplified products was monitored performing melting curves at the end of each amplification reaction. All amplicons generated a single peak, thus reflecting the specificity of the primers. Dexamethasone was used as a reference inhibitor of MMP-9 expression ( 80\% inhibition at $100 \mathrm{nM})$.

\section{Plasmid construction}

The DNA fragment corresponding to $1024 \mathrm{bp}$ of the 5'flanking region of the human MMP-9 promoter region (1005 to + 19) cloned into the PGL3-basic vector and the corresponding mutant construction in the $\mathrm{kB}$ site (GGAATTCCCC to GtcAacagCC) [25] were a kind gift of Dr. Siro Simizu (Antibiotics Laboratory and Chemical Biology Department, Saitama University, Japan). pNF$\kappa B$-luc containing the luciferase gene under the control of three $\mathrm{kB}$ responsive elements of the promoter of the Eselectin gene was a kind gift of N. Marx (Department of Internal Medicine II-Cardiology, Ulm, Germany).

\section{Assay of NF-KB and MMP-9 promoter activity}

The NF- $\mathrm{kB}$ and MMP-9 promoter activities were evaluated in 96-wells plates by means of transient transfection assays in THP- 1 cells by using the DEAE-dextran method as previously described [26]. Briefly, cells were exposed to a mixture of DNA-dextran $(750 \mu \mathrm{g} / \mathrm{ml}$ final concentration) for $30 \mathrm{~min}$ at $37^{\circ} \mathrm{C}$, using $700 \mathrm{ng} / \mathrm{ml} \mathrm{NF}-\mathrm{kB}$-luc and $500 \mathrm{ng} / \mathrm{ml}$ MMP-9-luc or mutated mкB-luc reporter plas$\mathrm{mid} / 1.5 \times 10^{5}$ cells. Cells were then incubated in FCSsupplemented RPMI 1640 (final volume, $100 \mu \mathrm{l} /$ well). 48 hours after cells were stimulated with $\mathrm{HZ}(6 \mu \mathrm{g} / \mathrm{ml})$ for four hours and treated with the fraction/compounds under study, as described for MMP-9 secretion. 48 hours after, $100 \mu \mathrm{l} /$ well Britelite plus (Perkin Elmer Waltham, MA, USA) was added and the plate read at the luminometer Victor ${ }^{\text {mI }} \mathrm{X} 3$ Perkin Elmer 2030 (Perkin Elmer Waltham, MA, USA). Parthenolide $(10 \mu \mathrm{M})$ was used as reference inhibitor of the NF- $\mathrm{KB}(\sim 50 \%$ inhibition) and MMP-9 ( 80\% inhibition) promoter activity. Data are expressed as mean \pm S.D. of triplicate samples.

\section{Statistical analysis}

All experiments were reproduced at least three times and, where indicated, representative experiments are shown. Statistical analyses were performed with GraphPad Prism 5 software, using 1-way ANOVA test followed by Bonferroni's post hoc test. The significance was indicated as follows: " $p<0.05$; ** $p<0.01$; *** $p<0.001$.

\section{Results}

Effect of Pg-FET on MMP-9 secretion and gene expression

In a preliminary experiment conducted in PMA-differentiated THP- 1 cells, $P g-\mathrm{MeOH}$ extract at $50 \mu \mathrm{g} / \mathrm{ml}$ inhibited the secretion of MMP-9 by $61 \%$. When the extract was deprived of tannins, the inhibitory effect was dramatically reduced $(-20 \%$, not statistically significant vs controls). This result indicated that tannins were likely to be the active principles. Therefore a fraction enriched in tannins $(P g$-FET) was prepared as described in the methodology section. To test $P g$-FET and individual compounds, undifferentiated THP-1 cells were stimulated with $\mathrm{Hz}$ or TNF. The concentration of $\mathrm{HZ}$ used in the experiments $(6 \mu \mathrm{g} / \mathrm{ml})$ reflects the levels of $\mathrm{Hz}$ likely to be present in the plasma of infected patients [27]. $\mathrm{Hz}$ induced a significant increase of the MMP-9 mRNA levels and the amount of protein secreted by THP-1 cells compared to controls (Figure 1). $P g$-FET, at 50 and 100 $\mu \mathrm{g} / \mathrm{ml}$, antagonized the increase of $\mathrm{Hz}$-induced MMP-9 secretion by $78 \%$ and $95 \%$, respectively, and the mRNA levels of $92 \%$ and $97 \%$, respectively (Figure 1). Similarly, in cells stimulated by TNF, $P g$-FET antagonized the increase of MMP-9 secretion by TNF, but the effect was significant only at the concentration of $100 \mu \mathrm{g} / \mathrm{ml}(-62 \%)$. As shown in Figure 2, $\mathrm{Hz}$ also induced a 2.5 fold increase of MMP-9 promoter activity, which was completely antagonized ( 80 and $90 \%$ inhibition) by $P g$-FET at 50 and $100 \mu \mathrm{g} / \mathrm{ml}$, respectively, thus confirming that the downregulation of MMP-9 secretion was consequent to a decreased rate of MMP-9 gene transcription.

\section{Effect of punicalagin, EA and urolithins on MMP-9 secretion and gene expression}

As previously reported, EA and punicalagin represent the $13.4 \%$ and $29.1 \%$ of $P g$-FET, respectively [5]. Punicalagin at 1 and $10 \mu \mathrm{M}$ inhibited the release of MMP-9 in Hz stimulated THP-1 cells by $38 \%$ and 79\%; the MMP-9 mRNA levels decreased accordingly $(-47 \%$ at $10 \mu \mathrm{M}$; Figure 3A-B). EA at 1 and $10 \mu \mathrm{M}$ inhibited the release of MMP-9 in Hz-stimulated THP-1 cells by 52 and $66 \%$, respectively, and the MMP- 9 expression by 56 and $65 \%$, respectively (Figure 3C-D). Ellagitannins were also able to affect MMP-9 transcription since EA inhibited $\mathrm{Hz}-$ induced promoter activity by $38 \%$ and $50 \%$ at 1 and 10 $\mu \mathrm{M}$, respectively, while the inhibitory effect of punicalagin was only statistically significant at $10 \mu \mathrm{M}(-65 \%)$ (Figure 4).

Urolithins A, B and 8ME at $25 \mu \mathrm{M}$ inhibited the release of MMP-9 in either $\mathrm{Hz}$ or TNF stimulated THP-1 cells, urolithins $\mathrm{A}$ and $\mathrm{B}$ being the most active $(-87,-37$, and $74 \%$, respectively; Figure $5 \mathrm{~A}$ ); the effect was associated to a decrease of MMP-9 mRNA levels (-88\%, $-95 \%$ and $-82 \%$ respectively; Figure 5B). Similarly urolithins A, B and 8- 


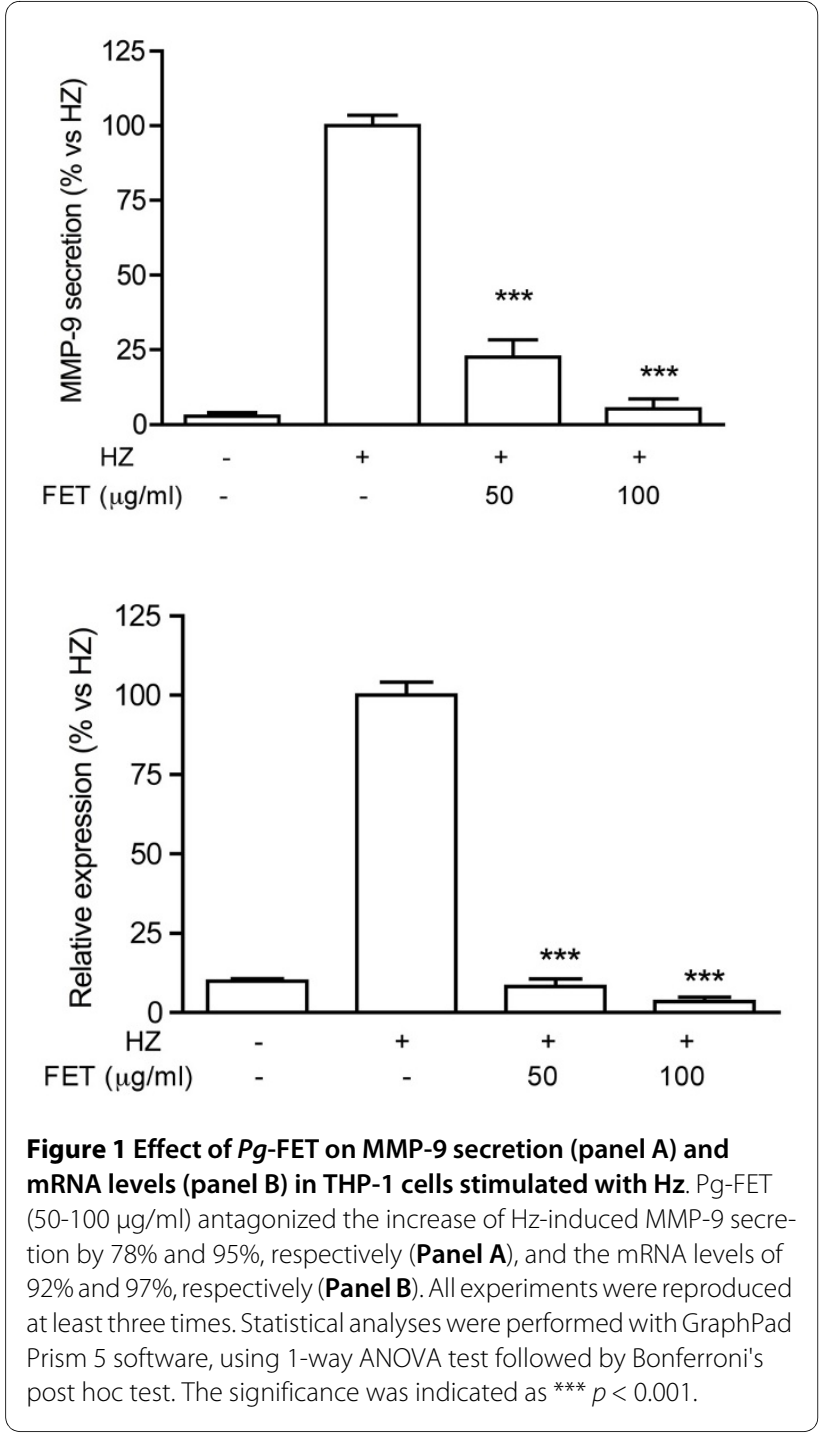

ME decreased the secretion of MMP-9 in cells stimulated with TNF (-58, -60 and $-44 \%$, respectively; Figure 6).

\section{Effect of Pg-FET and individual compounds on the NF-KB system}

To evaluate if $P g$-FET and individual components inhibited MMP-9 secretion and gene expression by acting on the NF- $\mathrm{KB}$ system, THP-1 cells were transiently transfected with a reported plasmid bearing the luciferase gene under the control of a promoter containing NF- $\mathrm{kB}$ binding sites. Transfected cell were then stimulated with $\mathrm{Hz}$ or TNF. As shown in Figure 7A, $P g$-FET, at 50 and 100 $\mu \mathrm{g} / \mathrm{ml}$, inhibited the $\mathrm{Hz}$-induced NF- $\mathrm{kB}$ promoter activity by $28 \%$ and $50 \%$, respectively. Both individual compounds at $1-10 \mu \mathrm{M}$ antagonized the $\mathrm{Hz}$-induced promoter activity: $-30 \%$ and $-41 \%$ for EA; $-32 \%$ and $-45 \%$ for punicalagin, respectively (Figure 7B). To further confirm that the inhibition of MMP-9 promoter activity reflected a down-regulation of the NF-kB system, $P g$-FET, EA, and

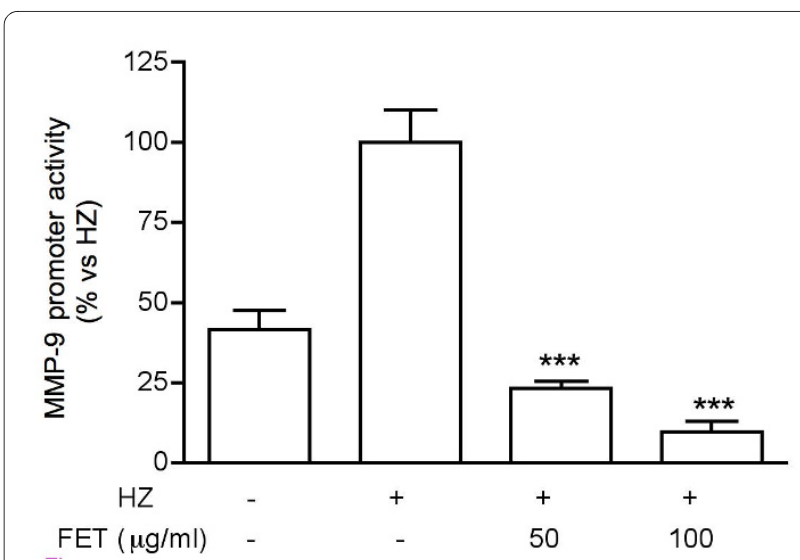

Figure 2 Effect of $\mathbf{P g}$-FET on Hz-induced MMP-9 promoter activity. $\mathrm{Hz}$ also induced a 2.5 fold increase of MMP-9 promoter activity, which was completely antagonized ( 80 and $90 \%$ inhibition) by Pg-FET at 50 and $100 \mu \mathrm{g} / \mathrm{ml}$, respectively. Parthenolide $(10 \mu \mathrm{M})$ was used as reference inhibitor of MMP-9 ( 80\% inhibition) promoter activity. Data are expressed as mean \pm S.D. of triplicate samples. All experiments were reproduced at least three times. Statistical analyses were performed with GraphPad Prism 5 software, using 1-way ANOVA test followed by Bonferroni's post hoc test. The significance was indicated as ${ }^{* * *} p<0.001$.

punicalagin were tested on THP-1 cells transfected with MMP-9 promoter mutated at the $\mathrm{kB}$ binding site $(\mathrm{m \kappa} B)$. As reported in Figure 8A, the mutated promoter activity was resistant to $\mathrm{Hz}$ induction in comparison to the wildtype (1.3 fold vs 2.5 fold increase) and the inhibitory effect by $P g$-FET was less pronounced as well (-20\% and $35 \%$ at 50 and $100 \mu \mathrm{g} / \mathrm{ml}$, respectively). Consistently with

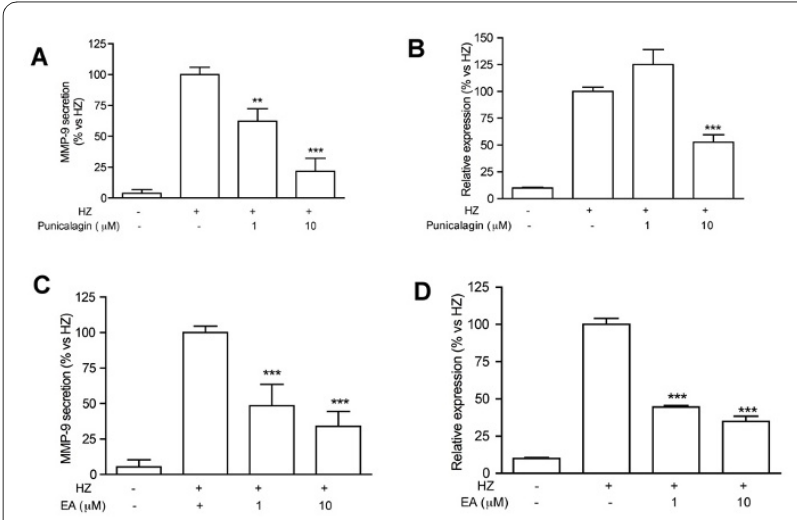

Figure 3 Effect of punicalagin and EA on MMP-9 secretion (panel $A, C)$ and mRNA levels (B, D) in THP-1 cells stimulated with $\mathrm{Hz}$. Punicalagin at 1 and $10 \mu \mathrm{M}$ inhibited the release of MMP-9 in Hz stimulated THP-1 cells by 38\% and 79\%; the MMP-9 mRNA levels decreased accordingly (-47\% at $10 \mu \mathrm{M}$; Figure 3A-B). EA at 1 and $10 \mu \mathrm{M}$ inhibited the release of MMP-9 in Hz-stimulated THP-1 cells by 52 and $66 \%$, respectively, and the MMP-9 expression by 56 and $65 \%$, respectively (Figure 3C-D). All experiments were reproduced at least three times. Statistical analyses were performed with GraphPad Prism 5 software, using 1-way ANOVA test followed by Bonferroni's post hoc test. The significance was indicated as follows: ${ }^{* *} p<0.01 ;{ }^{* * *} p<0.001$. 


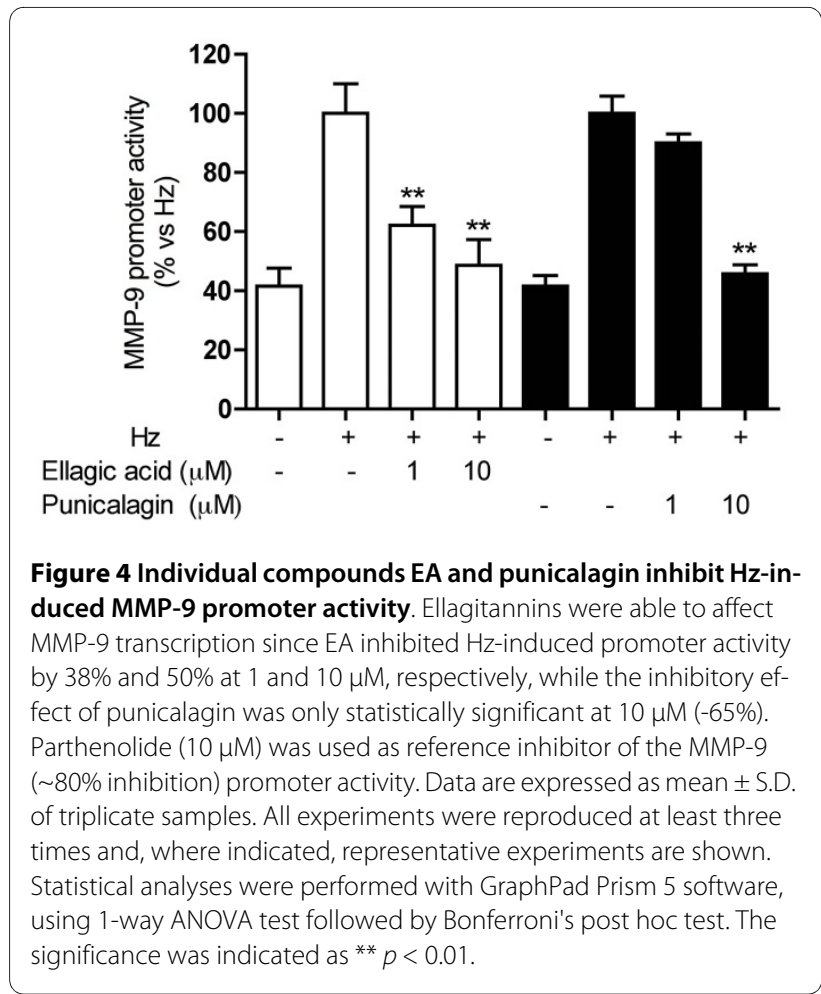

these results, punicalagin at $10 \mu \mathrm{M}$ inhibited the mutated promoter activity by only $25 \%$, and EA was inactive (Figure $8 \mathrm{~B})$.

\section{Discussion}

The sun-dried rind of the immature fruit of Punica granatum is used as an herbal anti-malarial remedy. The drug is rich in ellagitannins, namely EA, punicalagin, punicalin and EA glycosides [5]. In a previous work we demonstrated that the fraction enriched in tannins ( $P g$ FET) obtained from the methanolic extract of $P g$ inhibited in vitro the growth of $P$. falciparum asexual blood stages. According to previous results and those from other groups, ellagitannins and in particular EA, were identified as the active principles $[5,6,28,29]$

A phytocomplex, such as a herbal formulation, is characterized by a mixture of chemicals with a wide array of biological effects. The overall clinical effects of a phytocomplex represent a synthesis of several different activities exerted by clusters of molecules acting on different molecular targets. Therefore, it was expected that the anti-malarial activity of $P g$ could be attributed to the action of the components of the phytocomplex on other factors involved in the pathogenesis of the malarial disease and not only on the parasite itself. With this in mind, the possibility that $P g$-FET could interact with the production of MMP-9, an enzyme directly implicated in the pathogenesis of malaria was considered. MMP-9 expression is higher in mice brain with cerebral malaria [30] and
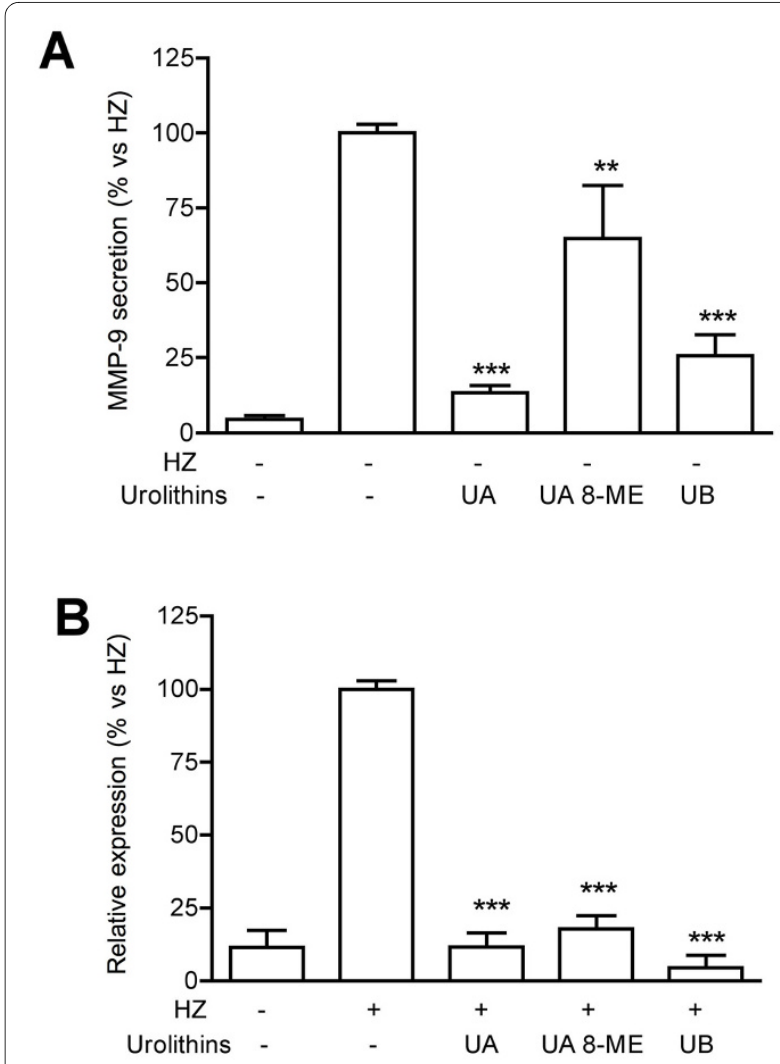

Figure 5 Effect of urolithins on MMP-9 secretion (panel A) and mRNA levels (panel B) in THP-1 cells stimulated with $\mathrm{Hz}$. Urolithins $\mathrm{A}, \mathrm{B}$ and $8 \mathrm{ME}$ at $25 \mu \mathrm{M}$ inhibited the release of MMP-9 in Hz-stimulated THP-1 cells, urolithins $A$ and $B$ being the most active $(-87,-37$, and $-74 \%$, respectively; Panel $\mathbf{A})$; the effect was associated to a decrease of MMP9 mRNA levels (-88\%, $-95 \%$ and $-82 \%$ respectively; Panel B). All experiments were reproduced at least three times. Statistical analyses were performed with GraphPad Prism 5 software, using 1-way ANOVA test followed by Bonferroni's post hoc test. The significance was indicated as follows: ${ }^{* *} p<0.01 ;{ }^{* * *} p<0.001$

human monocytes fed with $\mathrm{Hz}$ or trophozoite-parasitized red blood cells displayed increased activity and protein/mRNA expression of MMP-9 and increased production of TNF [11,12]. The enhancement of MMP-9 activity was causally related to the increase of IL-1 beta production. 15-HETE, one of the monohydroxy derivatives of polyunsaturated fatty acids (OH-PUFAs) attached to $\mathrm{Hz}$, was considered responsible for the increase of IL1beta production and MMP-9 activity [12].

The present data confirm that $\mathrm{Hz}$ or TNF increase the secretion and mRNA levels of MMP-9 in THP-1/monocytes. In addition, it has been shown that Pg-FET and individual compounds are able to antagonize such stimulation. The total fraction and the pure compounds inhibited $\mathrm{Hz}$ and TNF-induced MMP-9 promoter activity.

Considering that the level of EA and punicalagin measured in $P g$-FET is 13.4 and $29.1 \%$, the amount of $P g$-FET necessary to exert this effect is compatible with the con- 


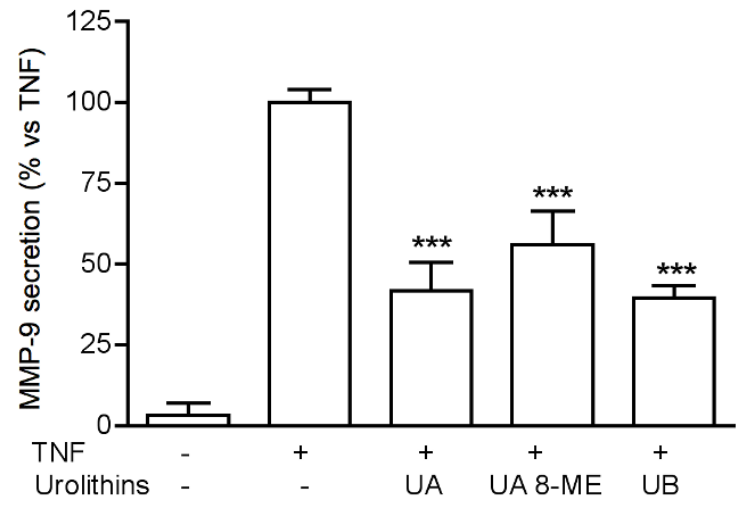

Figure 6 Effect of urolithins on MMP-9 secretion and mRNA levels in THP-1 cells stimulated with TNF. Urolithins A, B and 8-ME at $25 \mu \mathrm{M}$ decreased the secretion of MMP-9 in cells stimulated with TNF $(-58,-60$ and $-44 \%$, respectively). All experiments were reproduced at least three times. Statistical analyses were performed with GraphPad Prism 5 software, using 1-way ANOVA test followed by Bonferroni's post hoc test. The significance was indicated as ${ }^{* * *} p<0.001$.

centrations of EA and punicalagin necessary for the inhibition of MMP-9. It can then be concluded that EA and punicalagin greatly contribute to the overall effect exerted by $P g$-FET.

These two compounds are metabolized in vivo by the human intestinal microflora into at least three metabolites named urolithins [16-20]. It has been reported here that urolithins as well diminished MMP-9 secretion and mRNA levels induced by HZ or TNF. The effect could be observed at concentrations of metabolites $(25 \mu \mathrm{M})$ close to those attained in plasma $(18-20 \mu \mathrm{M})$ after pomegranate juice consumption [16]. These results suggest that also the metabolites of ellagitannins participate to the control of excessive production of MMP-9 and in turn they may protect against the increased production and function of the noxious cytokine TNF.

To investigate more deeply how $P g$-ellagitannins affect the signalling cascade leading to MMP-9 expression, the involvement of NF- $\mathrm{KB}$ system was investigated. It is known that several cytokines, including TNF, act at different levels ultimately promote the binding of the NF- $\mathrm{kB}$ complex to target sequences thus inducing the transcription of several genes, among which the MMP-9 gene. As in many other situations, in $\mathrm{Hz}$-fed murine macrophages, TNF up-regulation is linked to the activation of the NF$\kappa B$ pathway [31,32]. As already shown by Prato et al in human monocytes [12], Hz increased TNF levels in THP1 cells [33]. By showing that $P g$-FET and its ellagitannins inhibited NF- $\mathrm{kB}$ promoter activity and that the effect was evident only when the wild type promoter was used and less pronounced when the promoter was mutated for the NF- $\mathrm{kB}$ binding site, it has been demonstrated that $P g$ -

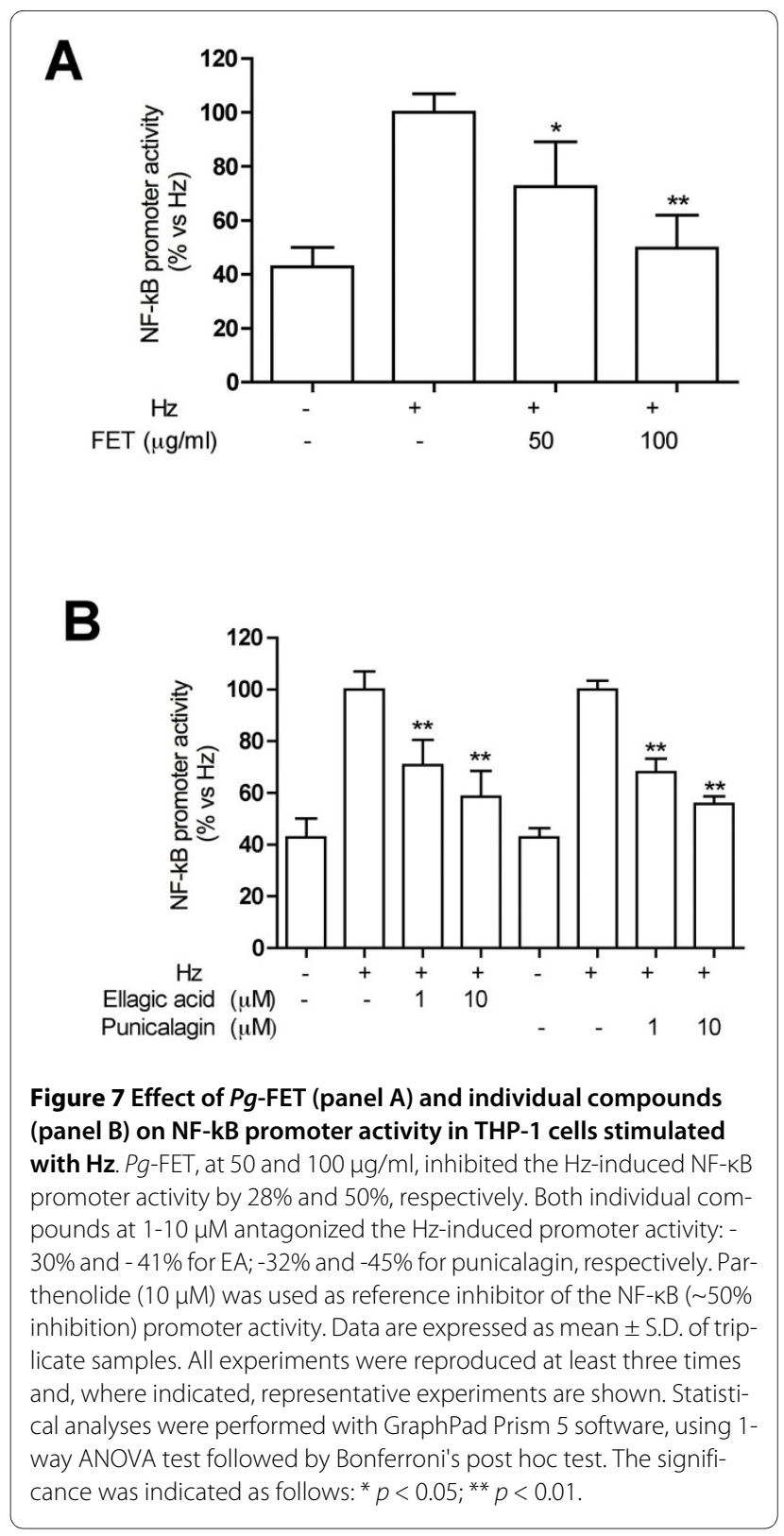

FET and ellagitannins block NF- $\mathrm{kB}$-driven transcription thus affecting the entire cytokine cascade. However, it could be predicted that their anti-inflammatory role goes beyond the effects on MMP-9.

In addition, ellagitannins and their hydrolysis products, i.e. EA, have been shown to inhibit the activation of inflammatory pathways including but not limited to the NF- $\mathrm{kB}$ system [34-36]. Thus, additional mechanisms of action could also be considered, such as mitogen-activated protein kinases (MAPK), which are modulated by pomegranate $[35,37,38]$. The peroxidation of the lipid components (HETEs) attached to $\mathrm{Hz}$ has been suggested to be instrumental for enhanced MMP-9 activity [12]. $P g$ FET is a mixture of polyphenols with high antioxidant 

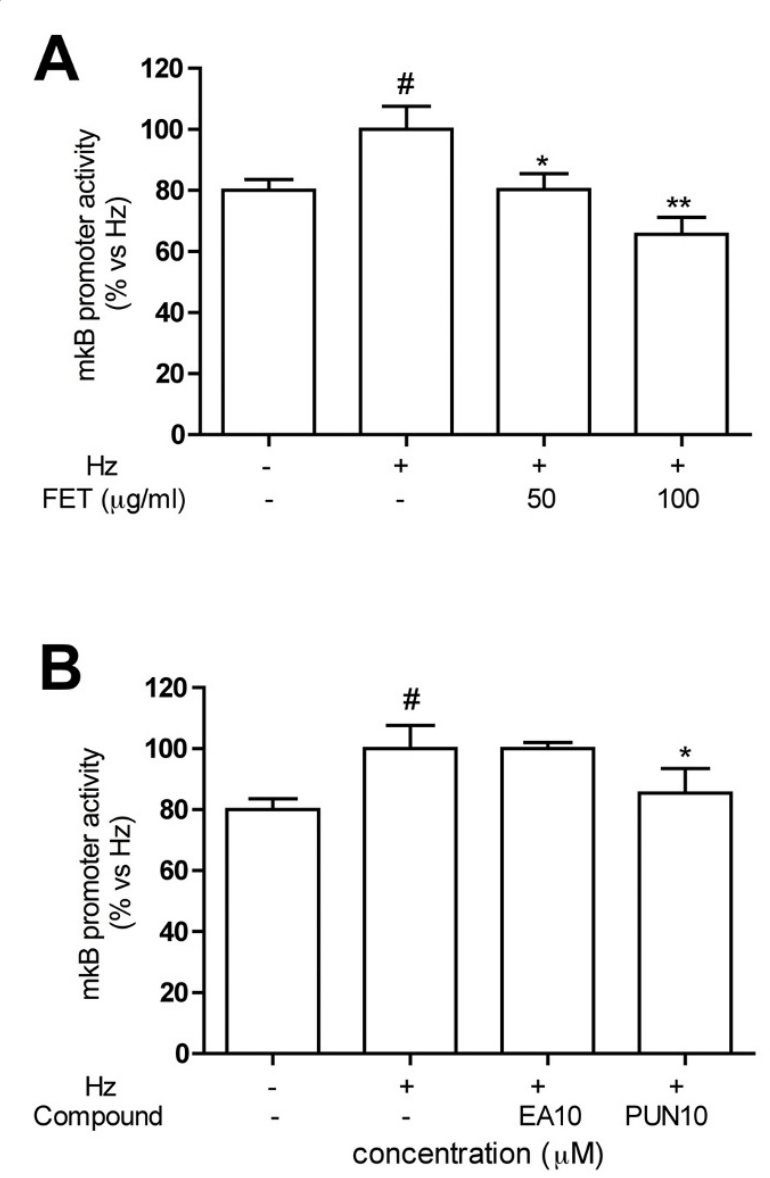

Figure 8 Effect of $P g$-FET (panel A) and individual compounds (panel B) on mkB promoter activity (MMP-9 promoter mutated in the $\mathrm{kB}$ site) in THP-1 cells stimulated with $\mathrm{Hz}$. The mutated promoter activity was resistant to $\mathrm{Hz}$ induction in comparison to the native promoter ( 1.3 fold vs 2.5 fold increase) and the inhibitory effect by PgFET was less pronounced as well $(-20 \%$ and $-35 \%$ at 50 and $100 \mu \mathrm{g} / \mathrm{ml}$, respectively). Punicalagin at $10 \mu \mathrm{M}$ inhibited the mutated promoter activity by only $25 \%$, and EA was inactive. Parthenolide (10 $\mu \mathrm{M})$ was used as reference inhibitor of the NF-KB ( 50\% inhibition) and MMP-9 ( $80 \%$ inhibition) promoter activity. Data are expressed as mean \pm S.D. of triplicate samples. All experiments were reproduced at least three times. Statistical analyses were performed with GraphPad Prism 5 software, using 1-way ANOVA test followed by Bonferroni's post hoc test. The significance was indicated as follows: ${ }^{*} p<0.05$; ${ }^{* *} p<0.01$; $\#<0.05$ vs $\mathrm{ctrl}$ without $\mathrm{Hz}$

capacity that are likely capable to prevent the non-enzymatic oxidation of PUFAs to hydroperoxides.

\section{Conclusions}

In conclusion, the beneficial clinical effects of the fruit rind of Punica granatum for the treatment of malaria possibly include the direct anti-parasitic activity and the ability to limit the excess inflammatory response of the host, thus limiting the risk of progression to the more severe form of the disease, including the onset of cerebral malaria.

\section{List of abbreviations}

(FET): Fraction enriched in tannins; (MMP-9): metalloprotease-9; (Pg): Punica granatum L.; (OMARIA): Orissa Malaria Research Indigenous Attempt; (IRBC): infected red blood cells; (Pf): Plasmodium falciparum ; (EA): Ellagic acid; (PMA): Phorbol myristate acetate; (Hz): Haemozoin; (FCS): foetal calf serum.

\section{Competing interests}

The authors declare that they have no competing interests.

\section{Authors' contributions}

MDA and GVG designed the research. GVG, MDA and MB performed the experiments. NB helped with the preparation of $\mathrm{Hz}$. DB supplied the plant and contributed to discussion of the data. MDA, DT and EB drafted and wrote the final manuscript. SR synthesized urolithins. All authors approved the final manuscript.

\section{Acknowledgements}

The authors wish to thank Elda Desiderio Pinto for excellent administrative assistance, the Indian Red Cross Society (Koraput District) and the Collectorate for long-years commitment. The authors thank Dr. Siro Simizu for donating the MMP-9 promoter. The financial support of the Università degli Studi di Milano (First 2006-2008) is also acknowledged. Part of this publication was generated in the context of the AntiMal project, funded under the 6th Framework Programme of the European Community (Contract N ${ }^{\circ}$ IP-018834). The authors are solely responsible for its content, it does not represent the opinion of the European Community and the Community is not responsible for any use that might be made of the information contained therein.

\section{Author Details}

1 Dipartimento di Scienze Farmacologiche, Università degli Studi di Milano, Via Balzaretti, 9 - 20133 Milano, Italy, ²Dipartimento di Sanità Pubblica-

Microbiologia-Virologia, Università degli Studi di Milano, Italy, ${ }^{3}$ Dipartimento di Scienze Farmaceutiche "Pietro Pratesi", Università degli Studi di Milano, Italy and ${ }^{4}$ Oddisi Research Laboratory, Kedar Gouri Road Bhubaneswar, 751002India

Received: 23 April 2010 Accepted: 19 July 2010

Published: 19 July 2010

\section{References}

1. Jurenka JS: Therapeutic applications of pomegranate (Punica granatum L.): a review. Altern Med Rev 2008, 13:128-144.

2. Gracious Ross R, Selvasubramanian S, Jayasundar S: Immunomodulatory activity of Punica granatum in rabbits--a preliminary study. $J$ Ethnopharmacol 2001, 78:85-87.

3. Bhattacharya D: A mixed Herbo-Chem-Anti-Malarial: Indicates cure \& Prophylaxis against Pf \& Pv; $>500$ cases in 5 yrs; Empirical basis of Holistic approach. Am J Trop Med Hyg 2003, 2003:484

4. Bhattacharya D: Punica Granatum as a human use, wide-spectrum prohylactic against malaria and viral diseases in India. Am Soc Trop Med Hyg 2004:288.

5. Dell'Agli M, Galli GV, Corbett Y, Taramelli D, Lucantoni L, Habluetzel A, Maschi O, Caruso D, Giavarini F, Romeo S, Bhattacharya D, Bosisio E: Antiplasmodial activity of Punica granatum L. fruit rind. $J$ Ethnopharmacol 2009, 125:279-285.

6. Verotta L, Dell'Agli M, Giolito A, Guerrini M, Cabalion P, Bosisio E: In vitro antiplasmodial activity of extracts of Tristaniopsis species and identification of the active constituents: ellagic acid and 3,4,5trimethoxyphenyl-(6'-O-galloyl)-O-beta-D-glucopyranoside. J Nat Prod 2001, 64:603-607

7. Gimenez F, Barraud de Lagerie S, Fernandez C, Pino P, Mazier D: Tumor necrosis factor alpha in the pathogenesis of cerebral malaria. Cell Mol Life Sci 2003, 60:1623-1635.

8. Clark IA, Budd AC, Alleva LM, Cowden WB: Human malarial disease: a consequence of inflammatory cytokine release. Malar J 2006, 5:85.

9. Bond M, Fabunmi RP, Baker AH, Newby AC: Synergistic upregulation of metalloproteinase- 9 by growth factors and inflammatory cytokines: an 
absolute requirement for transcription factor NF-kappa B. FEBS Lett 1998, 435:29-34

10. Slater AF, Swiggard WJ, Orton BR, Flitter WD, Goldberg DE, Cerami A Henderson GB: An iron-carboxylate bond links the heme units of malaria pigment. Proc Natl Acad Sci USA 1991, 88:325-329.

11. Prato M, Giribaldi G, Polimeni M, Gallo V, Arese P: Phagocytosis of hemozoin enhances matrix metalloproteinase-9 activity and TNFalpha production in human monocytes: role of matrix metalloproteinases in the pathogenesis of falciparum malaria. $J$ Immunol 2005, 175:6436-6442.

12. Prato M, Gallo V, Giribaldi G, Arese P: Phagocytosis of haemozoin (malarial pigment) enhances metalloproteinase-9 activity in human adherent monocytes: role of IL-1 beta and 15-HETE. Malar J 2008, 7:157.

13. Bellosta S, Dell'Agli M, Canavesi M, Mitro N, Monetti M, Crestani M, Verotta L, Fuzzati N, Bernini F, Bosisio E: Inhibition of metalloproteinase-9 activity and gene expression by polyphenolic compounds isolated from the bark of Tristaniopsis calobuxus (Myrtaceae). Cell Mol Life Sci 2003, 60:1440-1448.

14. Aslam MN, Lansky EP, Varani J: Pomegranate as a cosmeceutical source: pomegranate fractions promote proliferation and procollagen synthesis and inhibit matrix metalloproteinase-1 production in human skin cells. JEthnopharmacol 2006, 103:311-318.

15. Adams LS, Seeram NP, Aggarwal BB, Takada Y, Sand D, Heber D: Pomegranate juice, total pomegranate ellagitannins, and punicalagin suppress inflammatory cell signaling in colon cancer cells. J Agric Food Chem 2006, 54:980-985.

16. Cerda B, Espin JC, Parra S, Martinez P, Tomas-Barberan FA: The potent in vitro antioxidant ellagitannins from pomegranate juice are metabolised into bioavailable but poor antioxidant hydroxy-6Hdibenzopyran-6-one derivatives by the colonic microflora of healthy humans. Eur J Nutr 2004, 43:205-220.

17. Seeram NP, Lee R, Heber D: Bioavailability of ellagic acid in human plasma after consumption of ellagitannins from pomegranate (Punica granatum L.) juice. Clin Chim Acta 2004, 348:63-68

18. Seeram NP, Henning SM, Zhang Y, Suchard M, Li Z, Heber D: Pomegranate juice ellagitannin metabolites are present in human plasma and some persist in urine for up to 48 hours. J Nutr 2006, 136:2481-2485

19. Mertens-Talcott SU, Jilma-Stohlawetz P, Rios J, Hingorani L, Derendorf H: Absorption, metabolism, and antioxidant effects of pomegranate (Punica granatum l.) polyphenols after ingestion of a standardized extract in healthy human volunteers. J Agric Food Chem 2006 54:8956-8961

20. Seeram NP, Zhang Y, McKeever R, Henning SM, Lee RP, Suchard MA, Li Z, Chen S, Thames G, Zerlin A, et al:: Pomegranate juice and extracts provide similar levels of plasma and urinary ellagitannin metabolites in human subjects. J Med Food 2008, 11:390-394.

21. Trager W, Jensen JB: Human malaria parasites in continuous culture. Science 1976, 193:673-675.

22. Denizot $F$, Lang R: Rapid colorimetric assay for cell growth and survival. Modifications to the tetrazolium dye procedure giving improved sensitivity and reliability. J Immuno/ Methods 1986, 89:271-277.

23. Dell'Agli M, Bellosta S, Rizzi L, Galli GV, Canavesi M, Rota F, Parente R, Bosisio E, Romeo S: A structure-activity study for the inhibition of metalloproteinase-9 activity and gene expression by analogues of gallocatechin-3-gallate. Cell Mol Life Sci 2005, 62:2896-2903.

24. Bradford MM: A rapid and sensitive method for the quantitation of microgram quantities of protein utilizing the principle of protein-dye binding. Anal Biochem 1976, 72:248-254

25. Takagi S, Simizu S, Osada H: RECK negatively regulates matrix metalloproteinase-9 transcription. Cancer Res 2009, 69:1502-1508.

26. Dell'Agli M, Fagnani R, Galli GV, Maschi O, Gilardi F, Bellosta S, Crestani M, Bosisio E, De Fabiani E, Caruso D: Olive oil phenols modulate the expression of metalloproteinase 9 in THP-1 cells by acting on nuclear factor-kappaB signaling. J Agric Food Chem 2010, 58:2246-2252.

27. Keller CC, Kremsner PG, Hittner JB, Misukonis MA, Weinberg JB, Perkins DJ: Elevated nitric oxide production in children with malarial anemia: hemozoin-induced nitric oxide synthase type 2 transcripts and nitric oxide in blood mononuclear cells. Infect Immun 2004, 72:4868-4873.

28. Sturm N, Hu Y, Zimmermann H, Fritz-Wolf K, Wittlin S, Rahlfs S, Becker K: Compounds structurally related to ellagic acid show improved antiplasmodial activity. Antimicrob Agents Chemother 2009, 53:622-630
29. Soh PN, Witkowski B, Olagnier D, Nicolau ML, Garcia-Alvarez MC, Berry A, Benoit-Vical F: In vitro and in vivo properties of ellagic acid in malaria treatment. Antimicrob Agents Chemother 2009, 53:1100-1106.

30. Van den Steen PE, Van Aelst I, Starckx S, Maskos K, Opdenakker G, Pagenstecher A: Matrix metalloproteinases, tissue inhibitors of MMPs and TACE in experimental cerebral malaria. Lab Invest 2006, 86:873-888,

31. Jaramillo M, Gowda DC, Radzioch D, Olivier M: Hemozoin increases IFNgamma-inducible macrophage nitric oxide generation through extracellular signal-regulated kinase- and NF-kappa B-dependent pathways. J Immunol 2003, 171:4243-4253.

32. Jaramillo M, Godbout M, Olivier M: Hemozoin induces macrophage chemokine expression through oxidative stress-dependent and independent mechanisms. J Immunol 2005, 174:475-484.

33. Basilico N, Tognazioli C, Picot S, Ravagnani F, Taramelli D: Synergistic and antagonistic interactions between haemozoin and bacterial endotoxin on human and mouse macrophages. Parassitologia 2003, 45:135-140.

34. Lin CC, Hsu YF, Lin TC: Effects of punicalagin and punicalin on carrageenan-induced inflammation in rats. Am J Chin Med 1999, 27:371-376

35. Ahmed S, Wang N, Hafeez BB, Cheruvu VK, Haqqi TM: Punica granatum L. extract inhibits IL-1 beta-induced expression of matrix metalloproteinases by inhibiting the activation of MAP kinases and NFkappaB in human chondrocytes in vitro. J Nutr 2005, 135:2096-2102.

36. Larrosa M, Gonzalez-Sarrias A, Yanez-Gascon MJ, Selma MV, AzorinOrtuno M, Toti S, Tomas-Barberan F, Dolara P, Espin JC: Anti-inflammatory properties of a pomegranate extract and its metabolite urolithin-A in a colitis rat model and the effect of colon inflammation on phenolic metabolism. J Nutr Biochem 2009 in press. doi:10.1016/ j.jnutbio.2009.04.012

37. Afaq F, Saleem M, Krueger CG, Reed JD, Mukhtar H: Anthocyanin- and hydrolyzable tannin-rich pomegranate fruit extract modulates MAPK and NF-kappaB pathways and inhibits skin tumorigenesis in CD-1 mice. Int J Cancer 2005, 113:423-433.

38. Afaq F, Malik A, Syed D, Maes D, Matsui MS, Mukhtar H: Pomegranate fruit extract modulates UV-B-mediated phosphorylation of mitogenactivated protein kinases and activation of nuclear factor kappa B in normal human epidermal keratinocytes paragraph sign. Photochem Photobiol 2005, 81:38-45.

doi: 10.1186/1475-2875-9-208

Cite this article as: Dell'Agli et al., Ellagitannins of the fruit rind of pomegranate (Punica granatum) antagonize in vitro the host inflammatory response mechanisms involved in the onset of malaria Malaria Journal 2010, 9:208

\section{Submit your next manuscript to BioMed Centra and take full advantage of:}

- Convenient online submission

- Thorough peer review

- No space constraints or color figure charges

- Immediate publication on acceptance

- Inclusion in PubMed, CAS, Scopus and Google Scholar

- Research which is freely available for redistribution 